\title{
Pathogenic and Targetable Genetic Alterations in Resected Recurrent Undifferentiated Pleomorphic Sarcomas Identified by Targeted Next-generation Sequencing
}

\author{
BIQIANG ZHENG ${ }^{1,2}$, YUETING QU ${ }^{3}$, JIAN WANG $^{3}$, YINGQIANG SHI ${ }^{1,2}$ and WANGJUN YAN ${ }^{1,2}$ \\ ${ }^{1}$ Department of Musculoskeletal Cancer Surgery, Fudan University Shanghai Cancer Center, Shanghai, P.R. China; \\ ${ }^{2}$ Department of Oncology, Shanghai Medical College, Fudan University, Shanghai, P.R. China; \\ ${ }^{3}$ OrigiMed, Shanghai, P.R. China
}

\begin{abstract}
Background/Aim: Undifferentiated pleomorphic sarcomas (UPSs) are difficult to treat, with a high recurrence rate. However, the genetic and molecular characterization of recurrent UPS has not been identified. Patients and Methods: In this study, we investigated the pathogenic and targetable genetic alterations in 16 paired locally prerecurrent and post-recurrent UPS cases by targeted nextgeneration sequencing (466 genes). Results: Sequence variations were most frequently found in TP53 (66\%), ATRX (34\%), and RBI (28\%). In addition, for the first time, recurrent IL7R gene amplification (19\%) and KMT2C gene mutation (16\%) were detected in UPS. Interestingly, genetic alterations varied with tumor relapse. Importantly, targetable driver variants were found in recurrent UPS. Mutated genes were correlated with the cell cycle, PI3K/mTOR and RAS/MAPK signaling pathways. TMB was also found to be increased after tumor recurrence (4.6 vs. 7.5 mutations $/ M B$, $p=0.0343)$. Conclusion: Routine use of targeted nextgeneration sequencing for recurrent UPS can facilitate timely therapeutic decision-making.
\end{abstract}

Undifferentiated pleomorphic sarcoma (UPS) is one of the most common subtypes in soft-tissue sarcomas (STS), formerly known as malignant fibrous histiocytoma. Compared to other STS, UPS is more malignant, more

This article is freely accessible online.

Correspondence to: Dr. Wangjun Yan, Department of Musculoskeletal Cancer Surgery, Fudan University Shanghai Cancer Center, No 270, Dongan Road, Shanghai 200032, PR China. Tel/Fax: +86 2164430130, e-mail: spinetumor@163.com

Key Words: Soft tissue sarcoma, undifferentiated pleomorphic sarcoma, next generation sequencing, NGS, recurrence, targetable genetic alterations. cellular, and prone to local recurrence and distant metastasis, and the 5-year survival rates range from $30-50 \%$ (1).

UPS is heterogenous and characterized by complex karyotypes $(2,3)$, and no specific genetic characteristics have been defined. TP53, ATRX, and RBI have been identified as highly mutated genes (4). The Hippo, RAS/MAPK, and $\mathrm{PI} 3 \mathrm{~K} / \mathrm{mTOR}$ pathways are activated in UPS (5).

Currently, genetic data on UPS are scant or reported only in few cases $(3,4,6)$; few targetable driver mutations have been identified as targets for the treatment of UPS. UPS frequently displays infiltrative growth into the adjacent normal soft tissue, which results in a high local recurrence rate (7). However, pathogenic and targetable genetic alterations accompanied with UPS recurrence have not been characterized, which limits the development of therapeutic strategies. In this study, pathogenic and targetable genetic alterations in 16 paired locally pre-recurrent and postrecurrent UPS cases were investigated using targeted nextgeneration sequencing (466 genes). In addition, TMB related to UPS relapse was also analyzed. This study aimed to provide insight into clinically actionable drivers of recurrent UPS to facilitate targeted therapy.

\section{Patients and Methods}

Patients. The current study involved 16 patients with UPS who had undergone complete local resection twice in our hospital from April 2009 to April 2017. Diagnosis of UPS was established in accordance with the WHO Classification of Tumours of Soft Tissue and Bone, and was in accordance with the following criteria: 1) No identifiable line of differentiation; 2) Tumor cells showing a high degree of pleomorphism. Tumor, node, and metastasis (TNM) staging was determined using the 7 th edition of the American Joint Committee on Cancer guideline of TNM classification at the first surgery, in our hospital. Written informed consent was provided by all patients and the current study was approved by the Clinical Research Ethics Committee of Fudan University Shanghai Cancer Center (Number: 050432-4-1805C). 
Table I. Characteristics of patients.

\begin{tabular}{|c|c|c|c|c|c|c|c|c|}
\hline Patient ID & Gender & Age & Localization & $\begin{array}{c}\text { Status at } \\
\text { admission }\end{array}$ & $\begin{array}{l}\text { History of } \\
\text { treatment }\end{array}$ & $\begin{array}{l}\text { Treatment in } \\
\text { our hospital }\end{array}$ & $\begin{array}{l}\text { TNM } \\
\text { stage }\end{array}$ & Survival \\
\hline 1 & Male & 42 & Lower extremity & New & None & Both & II & Dead \\
\hline 2 & Male & 59 & Trunk & 2 times & None & None & III & Alive \\
\hline 3 & Male & 57 & Trunk & 6 times & None & Radio & III & Dead \\
\hline 4 & Male & 65 & Trunk & New & None & None & III & Alive \\
\hline 5 & Male & 64 & Trunk & 5 times & Both & None & III & Dead \\
\hline 6 & Female & 52 & Lower extremity & 1 time & None & None & II & Dead \\
\hline 7 & Male & 67 & Trunk & 2 times & None & None & III & Dead \\
\hline 8 & Male & 54 & Lower extremity & 2 times & Both & None & III & Dead \\
\hline 9 & Male & 71 & Lower extremity & 1 time & None & None & II & Alive \\
\hline 10 & Male & 49 & Lower extremity & 5 times & Chemo & Radio & III & Dead \\
\hline 11 & Male & 64 & Upper extremity & New & None & Chemo & III & Alive \\
\hline 12 & Male & 71 & Trunk & 3 times & Both & None & II & Alive \\
\hline 13 & Female & 64 & Hip & 3 times & Radio & None & II & Dead \\
\hline 14 & Male & 35 & Hip & 1 time & None & Chemo & III & Dead \\
\hline 15 & Male & 77 & Trunk & 3 times & None & None & III & Dead \\
\hline 16 & Female & 42 & Lower extremity & 1 time & None & Chemo & III & Alive \\
\hline
\end{tabular}

New: New diagnosis; times: the number of relapses at admission; Chemo: chemotherapy; Radio: radiotherapy; Both: chemotherapy and radiotherapy.

DNA extraction and targeted next-generation sequencing. Formalinfixed paraffin-embedded tissue blocks (16 paired pre-recurrent and post-recurrent UPS samples, matched adjacent normal muscle tissue samples) were obtained from the Pathology Department of Fudan University Shanghai Cancer Center. At least two 4- $\mu \mathrm{m}$ hematoxylin and eosin stained slides of each tumor block were reviewed, and only UPS tissue slides with $\geq 20 \%$ of tumor cells were further analyzed. Tumor genomic DNA was extracted from UPS tissue slices using QIAamp DNA FFPE Tissue Kit (Qiagen) according to the manufacturer's protocols. As a control of normal genomic DNA, at least three hematoxylin and eosin stained slides of adjacent muscle tissue block without tumor cells were used to extract normal genomic DNA.

The pre-recurrent UPS DNA, post-recurrent UPS DNA, and matched normal genomic DNA for each patient were analyzed by NGS-based ultra-deep panel sequencing (466 genes) in the College of American Pathologists certified laboratory of OrigiMed. Diluted libraries were sequenced to a mean coverage of $1000 \times$ on a NovaSeq for OrigiMed450. Resultant sequences were further analyzed for genomic alterations compared with normal genomic DNA, including single nucleotide variants, short and long insertions/deletions (indels), copy number variations, and structural variants of gene rearrangement/fusion. The tumor mutational burden (TMB) was estimated by analyzing somatic mutations, including coding base substitution and INDELs, per mega-base of the panel sequences examined.

Statistical analysis. Statistical analysis was performed using GraphPad Prism 5 (Graphpad Software, La Jolla, CA, USA). pValues were two-tailed and $p<0.05$ was considered statistically significant.

\section{Results}

Patient characteristics. A total of 16 patients with UPS who underwent complete local resection twice in our hospital were included in the study. Of the 16 patients, 3 were newly diagnosed at admission, and 13 cases had recurrent disease following previous surgery in external hospitals. The clinicopathological characteristics are listed in Table I. Five patients had chemotherapy and (or) radiotherapy history at admission. Six cases had undergone chemotherapy and (or) radiotherapy after the first surgery, but before UPS recurrence at our hospital. Ten patients had died at the last follow-up.

Pathogenic and targetable genetic alterations in paired prerecurrent and post-recurrent UPS. The landscape of genomic alterations in 16 pre-recurrent UPS and 16 post-recurrent UPS is displayed in Figures 1 and 2, respectively. Mutations were most frequently found in TP53, ATRX, and RB1 with rates of $69 \%$ and $62 \%$ (TP53), 31\% and 38\% (ATRX), and $31 \%$ and $25 \%(R B 1)$ in pre-recurrent UPS and paired postrecurrent UPS (Figures 1 and 2), respectively. IL7R gene amplification (19\%) and KMT2C gene mutation (16\%) were identified for the first time in UPS (Figure 3). Interestingly, there were 2, 2 and 2 patients displaying a new CDK6 gene amplification, FGF10 gene amplification, and RICTOR gene amplification after tumor relapse respectively, and two cases showed novel and different $P R K D C$ gene mutations after recurrence. In contrast, $B M X$ gene amplification was lost in two post-recurrent UPS cases (Figure 3 ).

Targetable driver variants identified in six recurrent UPS cases included a mutation in $I D H 2$, a truncation in TSC1, and amplifications in the VEGFA, KDR, FGFR2, CDK6, CCND1, KIT, PDGFRA, CD274, and MET genes. Information regarding the targetable driver variants is listed in Table II. Interestingly, genetic alterations varied with tumor relapse, 


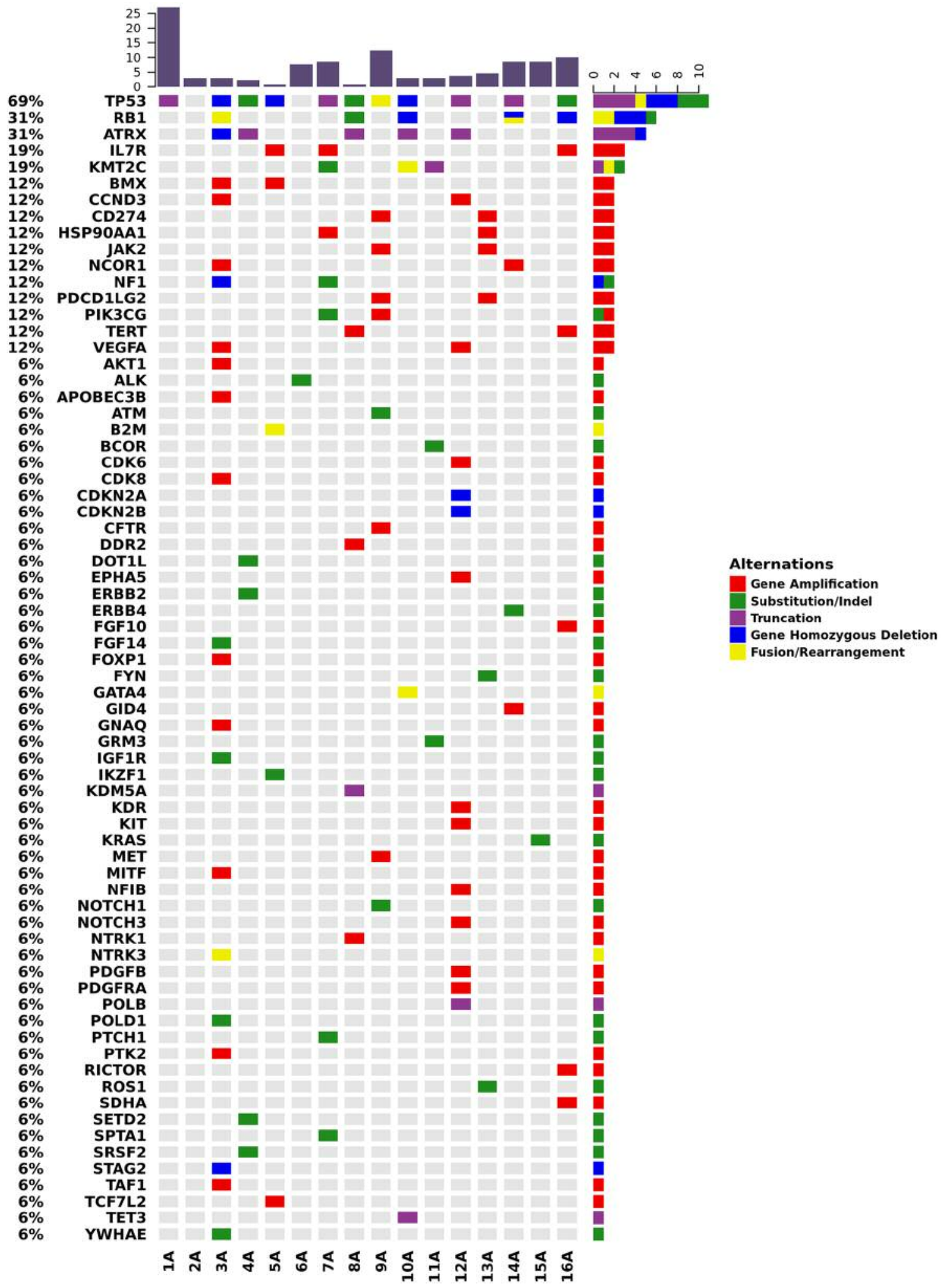

Figure 1. Landscape of genomic alterations in 16 patients with pre-recurrent UPS identified by targeted next-generation sequencing. Genomic alterations are annotated according to the color panel on the right of the image. Gene amplification (red), Substitution/Indel (green), Truncation (purple), Gene Homozygous Deletion (blue), Fusion/Rearrangement (orange). Alteration rates of genes are displayed on the left of the genomic alterations. Patient ID is shown on the bottom. A: Pre-recurrent UPS. 


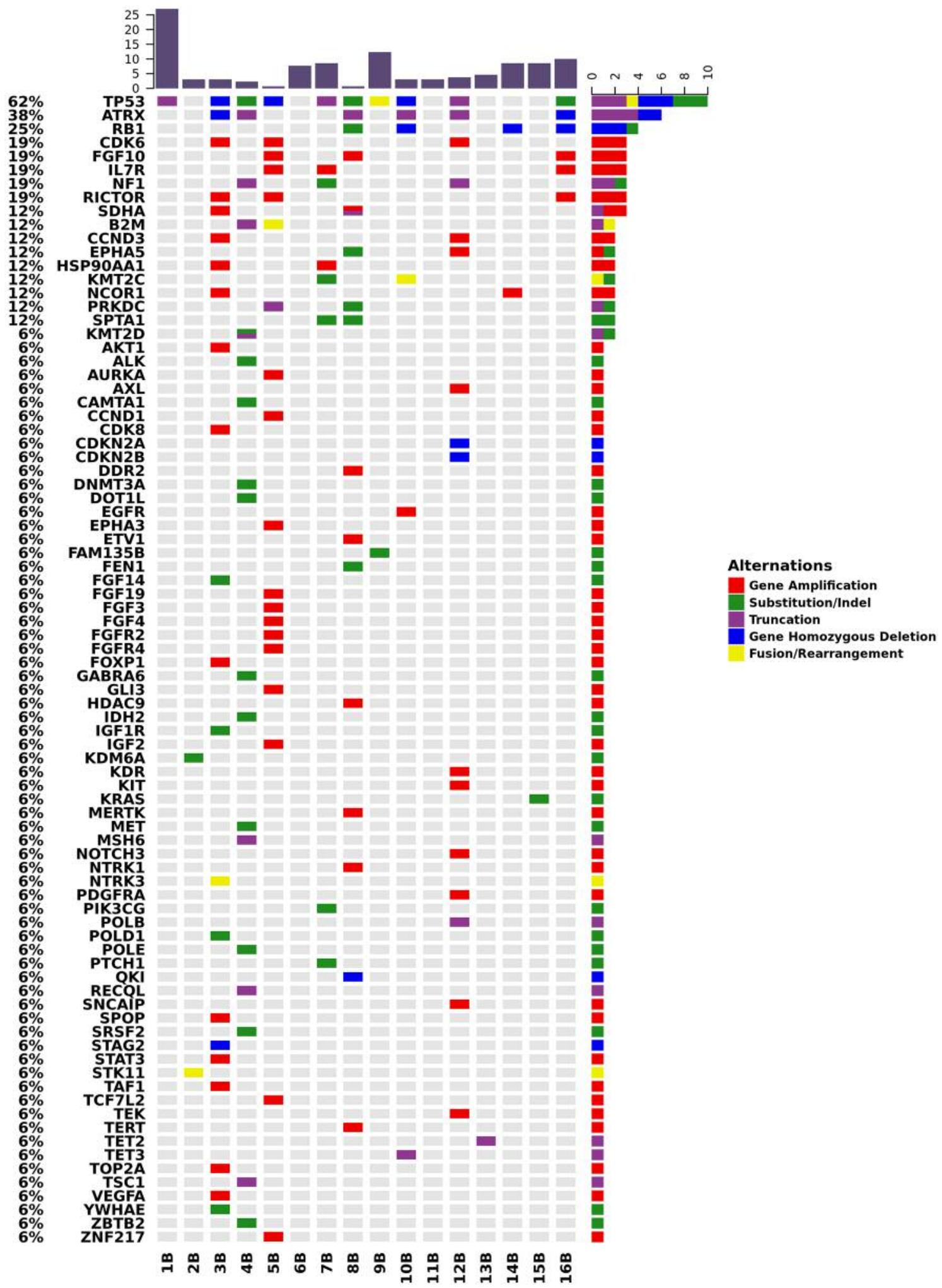

Figure 2. Landscape of genomic alterations in 16 patients with post-recurrent UPS identified by targeted next-generation sequencing. Genomic alterations are annotated according to the color panel on the right of the image. Gene amplification (red), Substitution/Indel (green), Truncation (purple), Gene Homozygous Deletion (blue), Fusion/Rearrangement (orange). Alteration rates of genes are displayed on the left of the genomic alterations. Patient ID is shown on the bottom. B: Post-recurrent UPS. 


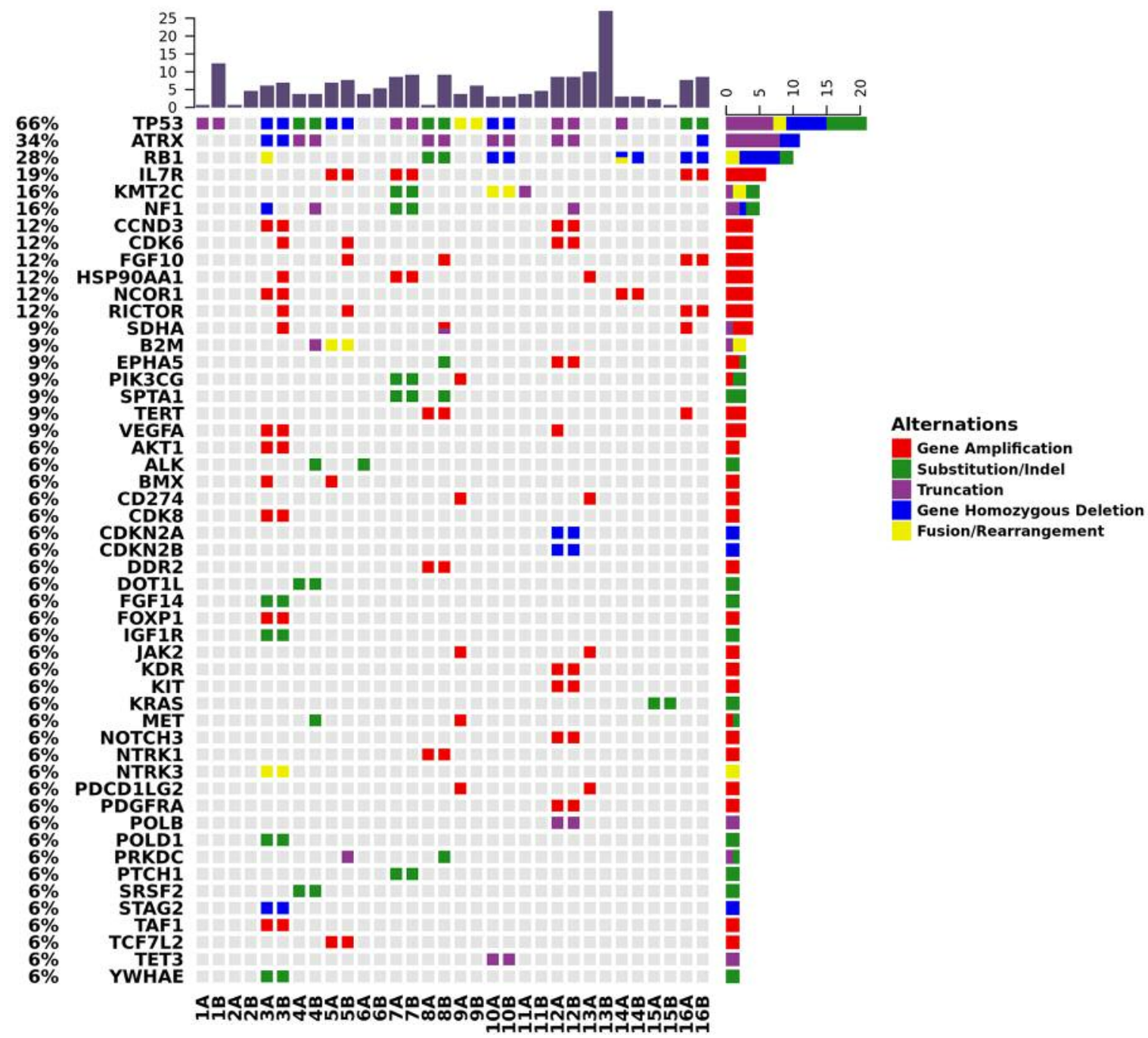

Figure 3. Landscape of genomic alterations in 16 paired pre-recurrent UPS and post-recurrent UPS identified by targeted next-generation sequencing. Gene alterations of 32 samples (16 paired) with no less than 2 in frequency were displayed. Genomic alterations were annotated according to the color panel on the right of the image: Gene amplification (red), Substitution/Indel (green), Truncation (purple), Gene Homozygous Deletion (blue), Fusion/Rearrangement (orange). Alteration rates of genes were displayed on the left of the genomic alterations. Patient ID is shown on the bottom. A: pre-recurrent UPS, B: post-recurrent UPS.

and three patients showed new targetable genetic alterations after relapse (in CDK6 for patient ID 3, in IDH2 and TSC1 for patient ID 4, in FGFR2, CCND1, and CDK6 for patient ID 5). However, three patients displayed targeted gene loss (CD274 and MET for patient ID 9, VEGFA for patient ID 12, $C D 274$ for patient ID 13). The genetic alterations in two cases (VEGFA for patient ID 3, PDGFRA, KIT, KDR, and $C D K 6$ for patient ID 12) were not changed after tumor recurrence. Also, of six cases, only one patient had undergone radiotherapy between two surgeries (patient ID 3).

Mutated genes are correlated with the cell cycle, PI3K/mTOR, and RAS/MAPK signaling pathways. It has been reported that
$\mathrm{PI} 3 \mathrm{~K} / \mathrm{mTOR}$ and RAS/MAPK signaling pathways are associated with UPS (5). In this study, the identified mutated genes were related to signaling pathways; the three strongest affected pathways were involved in cell cycle (TP53, CDK6, $C D K 8, C D K N 2 A, C D K N 2 B, C C N D 1), \mathrm{PI} 3 \mathrm{~K} / \mathrm{mTOR}(N F 1$, $S T K 11, T S C 1)$, and RAS/MAPK signaling pathways (NF1, $K R A S, M E T)$ (Table III). In addition, some gene variants (CDK6, CDK8, CDKN2A, CDKN2B, CCND1) associated with cell cycle regulation were detected for the first time in UPS.

$T M B$ is increased after tumor recurrence. TMB is a feasible predictor of response to anti-PD-1/PD-L1 (8, 9). Immunotherapy shows promise in the treatment of UPS and 

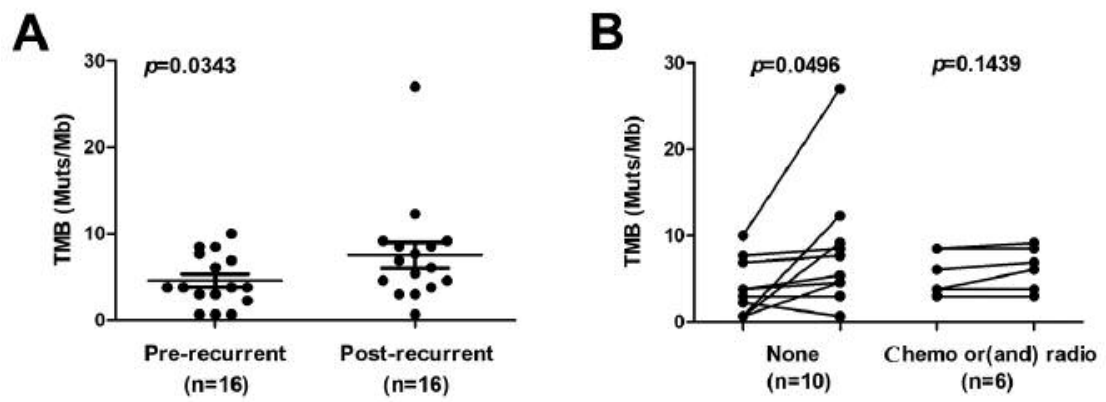

Figure 4.TMB is increased after tumor recurrence. (A) Comparison between the pre-recurrent UPS and post-recurrent UPS for TMB (mutations/MB). (B) Comparison of TMB between the pre-recurrent UPS and post-recurrent UPS according to patients who received treatment (chemotherapy and/or radiotherapy) or not in our hospital.

Table II. Targetable driver variants in recurrent UPS.

\begin{tabular}{|c|c|c|c|c|c|}
\hline Patient ID & Gene & Status at admission & Genetic alteration types & Pre-recurrent UPS & Post-recurrent UPS \\
\hline 3 & $V E G F A$ & 6 recurrence & Gene Amplification & Positive & Positive \\
\hline 3 & CDK6 & 6 recurrence & Gene Amplification & Negative & Positive \\
\hline 4 & $I D H 2$ & New diagnosis & Substitution/Indel & Negative & Positive \\
\hline 4 & TSC1 & New diagnosis & Truncation & Negative & Positive \\
\hline 5 & $F G F R 2$ & 5 recurrence & Gene Amplification & Negative & Positive \\
\hline 5 & CCND1 & 5 recurrence & Gene Amplification & Negative & Positive \\
\hline 5 & $C D K 6$ & 5 recurrence & Gene Amplification & Negative & Positive \\
\hline 9 & $C D 274$ & 1 recurrence & Gene Amplification & Positive & Negative \\
\hline 9 & $M E T$ & 1 recurrence & Gene Amplification & Positive & Negative \\
\hline 12 & PDGFRA & 3 recurrence & Gene Amplification & Positive & Positive \\
\hline 12 & KIT & 3 recurrence & Gene Amplification & Positive & Positive \\
\hline 12 & $K D R$ & 3 recurrence & Gene Amplification & Positive & Positive \\
\hline 12 & $V E G F A$ & 3 recurrence & Gene Amplification & Positive & Negative \\
\hline 12 & CDK6 & 3 recurrence & Gene Amplification & Positive & Positive \\
\hline 13 & $C D 274$ & 3 recurrence & Gene Amplification & Positive & Negative \\
\hline
\end{tabular}

Table III. Mutated genes correlated with the cell cycle, PI3K/mTOR, and RAS/MAPK signaling pathways in 16 paired UPS cases.

\begin{tabular}{|c|c|c|c|c|c|c|}
\hline \multirow{2}{*}{$\begin{array}{l}\text { Signaling pathway } \\
\text { Cell cycle }\end{array}$} & \multicolumn{5}{|c|}{ Related genes } & \multirow[b]{2}{*}{ CCND1 (1/32) } \\
\hline & TP53 (21/32) & CDK6 (4/32) & $C D K 8(2 / 32)$ & $C D K N 2 A(2 / 32)$ & $C D K N 2 B(2 / 32)$ & \\
\hline PI3K/mTOR & $N F 1(5 / 32)$ & RICTOR $(4 / 32)$ & STK11 (1/32) & TSC1 (1/32) & & \\
\hline RAS/MAPK & $N F 1(5 / 32)$ & $K R A S(2 / 32)$ & $M E T(2 / 32)$ & & & \\
\hline
\end{tabular}

dedifferentiated liposarcoma (10). Therefore, we determined whether TMB was related to UPS relapse, which may be managed with immunotherapy. We found that TMB was increased after tumor recurrence (average, $4.6 \mathrm{vs} .7 .5$ mutations/MB, $p=0.0343$, Figure 4A). Of 16 patients, 6 underwent post-operative treatment (chemotherapy and/or radiotherapy) between two surgeries in our hospital, TMB was significantly increased in patients who received no treatment (4.0 vs. 8.3 mutations/MB, $p=0.0496$, Figure 4B), whereas TMB was not obviously changed in patients who underwent chemotherapy and (or) radiotherapy (5.6 vs. 6.3 mutations/MB, $p=0.1439$, Figure 4B), suggesting that the treatment can guard against genetic mutations.

\section{Discussion}

Targeted next-generation sequencing is an accurate, costeffective, and clinically available approach for measuring 
targeted gene changes; it enables sequencing at greater depth with fewer samples, and in less time compared with whole exome sequencing. Currently, using targeted agents, especially in recurrent UPS, is relatively unknown. In this study, we for the first time investigated pathogenic and targetable genetic alterations by targeted next-generation sequencing (466 genes) in patients with recurrent UPS who experienced disease relapse more than once, and found targetable genetic alterations in recurrent UPS. Our study suggests that the use of targeted next-generation sequencing for recurrent UPS may be beneficial for these patients with poor prognosis

However, one recent study by Lewin et al. (6) does not support the routine use of targeted next-generation sequencing (48 genes) for UPS $(n=18)$, which is inconsistent with our results. The difference may be explained by several factors: 1) The targeted panels were different; our panel contained 466 genes. 2) Most of our patients had recurrent disease. 3) Maybe there were differences according to race. Our results are in line with current studies showing that TP53, $A T R X$, and $R B I$ are frequently mutated genes (4), and $\mathrm{PI} 3 \mathrm{~K} / \mathrm{mTOR}$ and RAS/MAPK signaling pathways are activated in UPS (5). Interestingly, targetable driver variants (IDH2 mutation, TSC1 truncation, VEGFA, KDR, FGFR2, CDK6, CCND1, KIT, PDGFRA, CD274, and MET gene amplification) were identified in recurrent UPS. For example, one relapsed case harboring the IDH 2 RI40Q mutation can be treated with enasidenib, which has been approved by the US Food and Drug Administration for patients with acute myeloid leukemia with $I D H 2$ mutations (11); of note, this mutation did not exist in the pre-recurrent UPS.

Immunotherapy has shown great promise in the management of many types of cancers (12), but only some patients respond to treatment. In addition to PD-L1 protein expression, an emerging biomarker for predicting response to immunotherapy is TMB $(8,9)$. High TMB is associated with better response rates to immunotherapy, as highly mutated tumors are more likely to harbor neoantigens, which can elicit antitumor $\mathrm{T}$ cell immunity $(13,14)$. Our results showed that TMB was increased after tumor relapse (average, 4.6 vs. 7.5 mutations $/ \mathrm{MB}, p=0.0343$, Figure 4A). It has been confirmed that TMB can be accurately assessed by targeted next-generation sequencing compared with whole exome sequencing (15). In various soft-tissue sarcomas, the benefit of immunotherapy with pembrolizumab is limited to patients with UPS and dedifferentiated liposarcomas (10). These data suggest that recurrent UPS may be suitable for treatment with immunotherapy.

UPS is particularly difficult to manage because of its high recurrence rate. Other than resection, effective management of UPS is lacking $(16,17)$. Targeted therapies show advantages in increasing effectiveness and reducing toxicity by suppression of a specific molecular aberration (18). In this study, pathogenic and targetable genetic alterations were identified in recurrent UPS, and the genetic alterations varied with tumor relapse. TMB was found to be increased after tumor recurrence. Our data support the notion that routine use of targeted next-generation sequencing for recurrent UPS can facilitate timely therapeutic decision-making.

\section{Conflicts of Interest}

The Authors disclose no potential conflicts of interest regarding this study.

\section{Authors' Contributions}

B. Zheng and W. Yan designed the experiments, interpreted the data, performed the statistical analysis and wrote the manuscript. B. Zheng, Y. Qu and J. Wang carried out experiments. Y. Shi collected the clinical data and provided material support.

\section{Acknowledgements}

Funding: This study was supported by Grants from the National Natural Science Foundation of China (Grant No: 81472480, 81302103).

\section{References}

1 Canter RJ, Beal S, Borys D, Martinez SR, Bold RJ and Robbins AS: Interaction of histologic subtype and histologic grade in predicting survival for soft-tissue sarcomas. J Am Coll Surg 210(2): 191-198 e192, 2010. PMID: 20113939. DOI: 10.1016/j.jamcollsurg.2009.10.007

2 Kelleher FC and Viterbo A: Histologic and genetic advances in refining the diagnosis of "undifferentiated pleomorphic sarcoma". Cancers (Basel) 5(1): 218-233, 2013. PMID: 24216705. DOI: $10.3390 /$ cancers5010218

3 Gibault L, Perot G, Chibon F, Bonnin S, Lagarde P, Terrier P, Coindre JM and Aurias A: New insights in sarcoma oncogenesis: A comprehensive analysis of a large series of 160 soft tissue sarcomas with complex genomics. J Pathol 223(1): 64-71, 2011. PMID: 21125665. DOI: 10.1002/path.2787

4 Cancer Genome Atlas Research Network: Comprehensive and integrated genomic characterization of adult soft tissue sarcomas. Cell 171(4): 950-965 e928, 2017. PMID: 29100075. DOI: $10.1016 /$ j.cell.2017.10.014

5 Serrano C, Romagosa C, Hernandez-Losa J, Simonetti S, Valverde C, Moline T, Somoza R, Perez M, Velez R, Verges R, Dominguez R, Carles J and Ramon YCS: Ras/mapk pathway hyperactivation determines poor prognosis in undifferentiated pleomorphic sarcomas. Cancer 122(1): 99-107, 2016. PMID: 26479291. DOI: $10.1002 /$ cncr.29733

6 Lewin J, Garg S, Lau BY, Dickson BC, Traub F, Gokgoz N, Griffin AM, Ferguson PC, Andrulis IL, Sim HW, Kamel-Reid S, Stockley TL, Siu LL, Wunder JS and Razak ARA: Identifying actionable variants using next generation sequencing in patients with a historical diagnosis of undifferentiated pleomorphic sarcoma. Int J Cancer 142(1): 57-65, 2018. PMID: 28891048. DOI: $10.1002 / \mathrm{ijc} .31039$ 
7 Song B, Lee K, Lee C and Moon KC: Prognostic significance of microscopic tumor extension in local recurrence of myxofibrosarcoma and undifferentiated pleomorphic sarcoma. Pathol Int 68(9): 509-516, 2018. PMID: 30094896. DOI: 10.1111/pin.12709

8 Johnson DB, Frampton GM, Rioth MJ, Yusko E, Xu Y, Guo X, Ennis RC, Fabrizio D, Chalmers ZR, Greenbowe J, Ali SM, Balasubramanian S, Sun JX, He Y, Frederick DT, Puzanov I, Balko JM, Cates JM, Ross JS, Sanders C, Robins H, Shyr Y, Miller VA, Stephens PJ, Sullivan RJ, Sosman JA and Lovly CM: Targeted next generation sequencing identifies markers of response to pd-1 blockade. Cancer Immunol Res 4(11): 959-967, 2016. PMID: 27671167. DOI: 10.1158/2326-6066.CIR-16-0143

9 Cristescu R, Mogg R, Ayers M, Albright A, Murphy E, Yearley J, Sher X, Liu XQ, Lu H, Nebozhyn M, Zhang C, Lunceford JK, Joe A, Cheng J, Webber AL, Ibrahim N, Plimack ER, Ott PA, Seiwert TY, Ribas A, McClanahan TK, Tomassini JE, Loboda A and Kaufman D: Pan-tumor genomic biomarkers for pd-1 checkpoint blockade-based immunotherapy. Science 362(6411): 2018. PMID: 30309915. DOI: 10.1126/science.aar3593

10 Tawbi HA, Burgess M, Bolejack V, Van Tine BA, Schuetze SM, Hu J, D'Angelo S, Attia S, Riedel RF, Priebat DA, Movva S, Davis LE, Okuno SH, Reed DR, Crowley J, Butterfield LH, Salazar R, Rodriguez-Canales J, Lazar AJ, Wistuba, II, Baker LH, Maki RG, Reinke D and Patel S: Pembrolizumab in advanced soft-tissue sarcoma and bone sarcoma (sarc028): A multicentre, two-cohort, single-arm, open-label, phase 2 trial. Lancet Oncol 18(11): 1493-1501, 2017. PMID: 28988646. DOI: 10.1016/S1470-2045(17)30624-1

11 Kim ES: Enasidenib: First global approval. Drugs 77(15): 17051711, 2017. PMID: 28879540. DOI: $10.1007 /$ s40265-017-0813-2

12 Sukari A, Nagasaka M, Al-Hadidi A and Lum LG: Cancer immunology and immunotherapy. Anticancer Res 36(11): 55935606, 2016. PMID: 27793882. DOI: 10.21873/anticanres.11144

13 Rizvi NA, Hellmann MD, Snyder A, Kvistborg P, Makarov V, Havel JJ, Lee W, Yuan J, Wong P, Ho TS, Miller ML, Rekhtman N, Moreira AL, Ibrahim F, Bruggeman C, Gasmi B, Zappasodi R, Maeda Y, Sander C, Garon EB, Merghoub T, Wolchok JD, Schumacher TN and Chan TA: Cancer immunology. Mutational landscape determines sensitivity to pd-1 blockade in non-small cell lung cancer. Science 348(6230): 124-128, 2015. PMID: 25765070. DOI: $10.1126 /$ science.aaa1348
14 McGranahan N, Furness AJ, Rosenthal R, Ramskov S, Lyngaa R, Saini SK, Jamal-Hanjani M, Wilson GA, Birkbak NJ, Hiley CT, Watkins TB, Shafi S, Murugaesu N, Mitter R, Akarca AU, Linares J, Marafioti T, Henry JY, Van Allen EM, Miao D, Schilling B, Schadendorf D, Garraway LA, Makarov V, Rizvi NA, Snyder A, Hellmann MD, Merghoub T, Wolchok JD, Shukla SA, Wu CJ, Peggs KS, Chan TA, Hadrup SR, Quezada $\mathrm{SA}$ and Swanton C: Clonal neoantigens elicit $t$ cell immunoreactivity and sensitivity to immune checkpoint blockade. Science 351(6280): 1463-1469, 2016. PMID: 26940869. DOI: $10.1126 /$ science.aaf 1490

15 Chalmers ZR, Connelly CF, Fabrizio D, Gay L, Ali SM, Ennis R, Schrock A, Campbell B, Shlien A, Chmielecki J, Huang F, He Y, Sun J, Tabori U, Kennedy M, Lieber DS, Roels S, White J, Otto GA, Ross JS, Garraway L, Miller VA, Stephens PJ and Frampton GM: Analysis of 100,000 human cancer genomes reveals the landscape of tumor mutational burden. Genome Med 9(1): 34, 2017. PMID: 28420421. DOI: 10.1186/s13073-0170424-2

16 Clark MA, Fisher C, Judson I and Thomas JM: Soft-tissue sarcomas in adults. N Engl J Med 353(7): 701-711, 2005. PMID: 16107623. DOI: $10.1056 /$ NEJMra041866

17 Nakamura T, Oi T, Asanuma K, Hagi T and Sudo A: Tumor resection may improve survival in patients with soft tissue sarcoma aged 75 years and older. Anticancer Res 39(1): 331334, 2019. PMID: 30591476. DOI: 10.21873/anticanres.13115

18 Sawyers C: Targeted cancer therapy. Nature 432: 294, 2004. PMID: 15549090. DOI: 10.1038/nature03095 